\title{
Space, Entrepreneurial Ecosystems Dynamics, and Interspecific Ecological Interactions
}

\begin{abstract}
This paper aims at investigating entrepreneurial ecosystems through analysis of interactions among their main agents, in different spatialities of a medium-size city: the city center (downtown), a suburban street, and its main shopping mall. As a theoretical framework the Jacobs approach (2011), the theory of practical action (Bourdieu, 2010), and the theory of interspecific ecological interactions (Lopes \& Russo, 2010) were used. In methodological terms, a case study approach was carried out. The findings indicate different types of ecosystem interactions, considering the influence of the context, technology, and innovation as well as the historical trajectories and Habitus that characterize them.
\end{abstract}

Keywords: Entrepreneurial Ecosystems; Interspecific Ecological Interactions; Spatial Vitality; Habitus. 


\section{INTRODUCTION}

The study of the influence of spatial conditions where there is established or newcomers business, carries as its focus the analysis of different authors, especially those interested in the search for a better understanding of the factors of vitality and mortality of enterprises (Bataglia, Franklin, Caldeira, Silva, Heber, 2014; Tureta, Rosa, Ávila, 2006). Among these authors, a significant range highlights the theory of organizational ecology (Lopes \& Rosso, 2010; Baum, 1999; Moore, 1993; Hannan \& Freeman, 1977) as an important landmark of research on the theme, especially if regarding the current moment, marked by increasingly dynamic changes arising from socioeconomic environments.

In this context, space is characterized by a specific locus of study, such as a neighborhood, a street, or a city (Jacobs, 2011). However, the environment is characterized by the specific conditions present in a certain space (Törnroos, Halinen, Medlin, 2016). Moreover, the notion of agent comprises the individuals that interact with the environment, modifying it and being modified by it (Thiry-Cherques, 2006). Finally, the ecosystem is commonly understood as the result determined by the dynamics between the environment and the agents in a certain space.

Such notions find significant convergence within the scope of contemporary studies as those of research programs designed to investigate the relationships between the constructs Space and Social Action, associated with processes of reconversion of the economic functions of cities and gentrification.

Within the extent of such studies, while investigating the dynamics of reconversion of economic functions in a Brazilian city guided by a process of late industrialization, from the perspective of different social agents involved in it, mismatches, and contradictions in the demands 
of the socioeconomic and spatial contexts could be identified. As an example, the study reports the downtown versus suburban area antinomies, meaning there is loss of attractiveness in the central region (downtown) as place of residence, contributing to the emergence of new centralities, especially in the areas of accessibility and in the surroundings of large industrial plants, recently installed, as well as in neighborhoods and housing complexes designed to shelter workers from around. A clear evidence of this urban conjuncture - the expansion of cities and creation of new centralities - was the relevance gained by a street subsequently investigated: Santa Juliana Street.

This street is portrayed as chaotic and linked to characteristics such messiness, ugliness, filth, disorganization, and disorder due to its intense traffic. Its varied commerce, the mixture of buildings and squats, different architectural styles, the confluence of people of different social classes, behavior, taste, and propensities regarding consumption present characteristics of growth models applied to suburban streets of popular commerce, without proper urban planning and out of the range of control and care from the public sector (organic development processes).

The case studied also raise the matter of how different local entrepreneurial ecosystems are built and sustained (Spigel, 2017; Kanter, 2012; Baum, 1999; Hannan \& Freeman, 1977), as well as they incite curiosity concerning the possibility of studying forms of relationships between people and businesses in spaces other than a street of popular commerce, seeking to categorize them into different types of ecosystems (Lopes \& Rosso, 2010; Hess, 2004; Håkansson \& Snehota, 1995).

Under the light of this challenge, in addition to Santa Juliana Street, an analysis of two other spaces in the city of Sete Lagoas is proposed: Its main commercial center (downtowm), an environment widely known for its location and tradition; and a modern shopping mall. Once the research spaces have been traced, a question that is the application of the scope of this study arises: 
In what way relationships between different entrepreneurs (Bourdieu, 2008) and environment (Jacobs, 2011), in each space, have produced unique ecosystems, typified in the interspecific ecological interactions (Lopes \& Rosso, 2010)?

Regarding its main purpose, in accordance with the matter of the formulated research, the present study consisted of investigating how different groups of entrepreneurs and environments interact and configure different entrepreneurial ecosystems. This, adopting as premises that different entrepreneurs, when articulating in a certain space, mobilizing different capital economic, cultural, social, and symbolic (Bourdieu, 2008) - produce different interspecific ecological interactions (Lopes \& Rosso, 2010).

As for its relevance, it aims at expanding research on the multiplicity of interrelations that forge the contemporary socio-spatial dynamics (Jacobs, 2011). It is possible to observe a certain lack of studies aimed at investigating the influence of spatiality - and the relationship between these and the various agents that interact within them - on the construction of entrepreneurial ecosystems.

Another contribution comes from the incorporation of approaches around interspecific ecological interactions - as considered by the theory of organizational ecology, adding new possibilities of intra and interorganizational analysis. Through this study, it is encouraged that such socio-spatial analysis devices help public leaders, entrepreneurs, and other social agents to formulate more synergistic strategies among societal, organizational, and individual instances. 


\section{SPATIAL FACTORS OF DIVERSITY AND VITALITY}

To investigate the entrepreneurial ecosystems targeted by this study, the theoretical framework of Jacobs (2011) was considered a milestone. According to this author, there are four spatial conditions that are indispensable for generating diversity and vitality in urban spaces as follows:

Condition 1: The street or district, and undoubtedly the largest possible number of segments that compose it, should serve more than one main function: preferably, more than two.

Condition 2: Most street blocks should be of short distance; That is, the streets and the opportunities to turn around the corners should be frequent.

Condition 3: The street or district must have a combination of buildings from varying times and conservation states, and include a good percentage of old buildings, to generate a varied economic income. This mixture should be compact.

Condition 4: There must be a highly enough density of people, whatever their purposes. This includes a high concentration of people whose purpose is to live there. 


\section{BOURDIEU'S THEORY OF PRACTICAL ACTION}

As a foundation for the process of investigating the interactions between the entrepreneurs in the ecosystems of this study the theory of practical action, developed by Pierre Bourdieu was used. Bourdieu (2010, 2008, 2006) defends the idea of a more practical and dynamic social science, breaking with the determinist constructs of structuralism that were the norm until then, and which comprehends the subject in a mainly passive way while facing social structures. The author understands that such structures are shaped by the constant interaction between the environment, and what he calls agents, which are endowed with a historical sense, interests, and action in the social field unlike the structuralist subject, referring to a more passive being in History (ThiryCherques, 2006).

The afore mentioned social agents are then endowed either with similar or distinct Habitus, as well as unevenly distributed capitals, in interrelated situations within a given social space, where conflicts and coalition unfold in the pursuit of the maintenance or transformation of the prevailing state of power and/or domination (Bourdieu, 2010, 1996).

Bourdieu (1996, 2010) defines Habitus as a system of longstanding dispositions and principles, which remain in time in certain environments and rules their behavior, their

functioning, therefore acting as structuring structures, that is, as generating and organizing schemes of collective and individual actions.

Under this perspective, Habitus is defined as a set of principles of global vision, personal taste and preferences that guide individual choices and actions within a determined scope. Social actors with different Habitus tend, therefore, to behave in different manners. As for the delineated scope, it comprises a multidimensional, dynamic space, composed of several distinct dimensions 
- economic, social, symbolic, cultural - and it is determined by the volume of capital held by each of its agents and forces (Bourdieu, 1994).

The understanding of the concept of capital is essential to the understanding of Bourdieu's work. Capital is defined as the main form of power within a field being both an instrument and an object of dispute. Bourdieu (2008) presupposes the existence of four types of capital (economic, social, cultural, and symbolic). In defining the types of capital proposed by Bourdieu (2008), it may be done as follows:

1. Economic capital: resources associated with factors of production (land) and economic assets, such as material goods;

2. Social capital: it involves the maintenance of social relations, based on obtaining benefits obtained by a particular subject or group when establishing such relationships;

3. Cultural capital: a set of knowledge and intellectual qualifications transmitted by family and education institutions throughout the life of the subject. This capital can acquire three forms: the incorporated state, associated to longstanding characteristics of the body (the form of speech, family habits); the objective state, such as the possession of cultural goods (works of art); and, the institutionalized state, as academic titles; 
4. Symbolic capital: related to the accumulation of prestige and social recognition by an individual who keeps under his control the resources considered essential in each field.

\section{INTERSPECIFIC ECOLOGICAL INTERACTIONS}

Inserted in the context of studies about organizational ecology, initially known as ecology of populations (Bataglia et al., 2009; Pina, 1999; Silva \& Heber, 2014; Tureta et al., 2006), the contributions on Interspecific Ecological Interactions (IES) offer to investigate intervening factors in the processes that result in a great number of organizations within the same context.

According to Bataglia et al. (2009, p. 137), the perspective of organizational ecology is based on "[...] the theoretical questioning of the assumption of the organization's adaptability to its environment". To Hannan and Freeman (1977), the survival of an organization would depend on the nature of the environment and its competitive situations. The concept of selection, applied to organizational ecology, would mean that the environment selects organizations, causing their survival and death, leading to evolution. Such a theory would be based on the economic theory of the firm and is inspired by the idea of Darwin's natural selection.

The environment in this context would then have a deterministic character in organizational survival, since it would select those organizations most apt to survive in a specific context, with the organization having little influence on its destiny. In this context, managers would be essentially passive agents whose function would be to react to changes in the external environment. Understanding the environment as a protagonist in organizations' survival processes, Hannan and Freeman (1977) suggest that populations should be considered to understand the changes that 
affect organizations, and that the changes that occur in them could not be comprised in a singular neither an isolated form.

In other words, the variations found in organizations would be linked to environmental changes, bringing either benefits or losses to them, and positive changes would tend to be replicated by other organizations present in the environmental context, thus making movements in systems, in organizations, in chains, in communities, and in populations. In this sense, organizations in the same space and that are under the same environmental conditions would tend to be isomorphic, that is, they should present similar characteristics. Organizational survival would then be directly influenced by the ability of individuals and organizations to perceive whether variations will be successful or which strategies they can adopt to keep up with changes in uncertain and unstable environments (Lopes \& Rosso, 2010; Baum, 1999).

Therefore, the adoption of the model of categorization of ecosystems formed by the interaction between entrepreneurs in different spaces based on interspecific ecological interactions, in order to analyze the way different "species" interact among them in an environment, presented appropriate as a basis for analyzing the relationship between different businesses within the same space. These businesses would so configure, as an analogy, different "species" (Lopes \& Rosso, 2010)

These ecological interactions may be categorized into harmonious and inharmonious, and in the first, species coexist harmoniously and, in the second, there is friction between them (Lopes \& Rosso, 2010). Through this perspective, the Lopes and Rosso (2010) approach was used as conceptual model of IEIs. Configured in eight types - four inharmonious (Amensalism or Antibiosis, Predation, Parasitism, Slavery), and four harmonious (Symbiosis or Mutualism, Protocooperation, Inquilinism or Epyhitism, Commensalism)- it results in eight types of IEIs. 


\section{METHOD}

The research may be characterized as a case study, of qualitative approach and descriptive character, carried out through semi-structured and in-depth interviews with local entrepreneurs who were active in the entrepreneurial ecosystems surveyed: downtown, suburban peripheral street, and shopping mall, in the city of Sete Lagoas, at Minas Gerais State (Brazil).

The data collection followed best practices in qualitative inductive methods (Denzin \& Lincoln, 2000; Emerson, Fretz, Shaw, 1995; Glaser \& Strauss, 1967; Patton, 1990). First, we gathered as much formal historical data about the city and sites under investigation, its people, and its surroundings as possible. As result, it allowed us to construct a historical timeline and picture of the evolution of the sites targeted, including the role entrepreneurs played. Second, it allowed us to follow the recommendations of Benbasat et al. (1987) to scan newspapers and directories, as well as talking with local entrepreneurs. This approach allowed us to engage in purposive sampling (Glaser \& Strauss, 1967) to identify and subsequently interview a cross-section of entrepreneurs who have founded and are currently involved in a variety of business enterprises throughout the town.

At the end, 49 entrepreneurs were interviewed, mostly linked to local businesses, defined through accessibility and convenience. The interviewees were identified by numbers from one to 49, one to 24 being from Santa Juliana Street, 25 to 38 from downtown and 39 to 49 from the shopping mall, in over 110 hours of recorded interviews.

The interview data was complemented by an additional 40 hours of field observation where we took detailed field notes related to the layout of the areas under investigation, the location, 
approximate age, style, usage and distribution of its buildings, groupings of businesses and their clientele, size and character of neighborhoods, behavior and interactions of the habitants, visitors, and entrepreneurs. Included in these 40 hours were several walkabouts through the city as a whole, meals in local restaurants, use of both public and private transportation and assessing the time it takes to move between neighborhoods and buildings, identifying flows of people and vehicles, describing the architectural and decorative features of landmarks, neighborhoods, and streets, observing how the types and numbers of people that moved through different areas of the city, and generally analyzing the uses of its physical spaces.

All the interviews were professionally transcribed and yielded a total of 642 pages of text. As our data collection unfolded, we surveyed pertinent literature on entrepreneurship, ecosystem development, and work from related disciplines (e.g., sociology, political science) and reoriented our last interviews based on the insights gleaned from constant comparison between interviews and iterating between our data and the literature (Denzin \& Lincoln, 2000). As part of this process, we interpreted and reinterpreted our results several times by writing working papers, discussing our study with interested colleagues, and following-up emerging concepts in subsequent interviews and queries at the research sites.

The interview script was designed in order to contemplate the categories of analysis advocated in the present study, which are capital - social, economic, cultural and symbolic - as advocated by Boudieu (2008); the conditions of diversity and vitality - diversity of functions, short distance blocks, mixture of new and old buildings and flow of people - raised by Jacobs (2011); and the framing of one type of interspecific ecological interaction - Mutualism, Protocooperation, Inquilinism, Commensalism, Amensalism, Predation, Parasitism - as proposed by Lopes and Rosso (2010), as indicated in Figure 1. 
Insert Figure 1 about here.

\section{THE SETE LAGOAS CASE}

Sete Lagoas is located $70 \mathrm{~km}$ away from the capital of the State of Minas Gerais, Belo Horizonte (Brazil). Its privileged location near the capital, the international airport, and on the banks of BR 040 highway, which links to metropolis such as Brasília and Rio de Janeiro, Sete Lagoas impresses by holding a strategic character for the location of several projects, allowing the rapid flow of products locally produced. In addition, the city holds an area of influence composed of 38 municipalities and approximately 500 thousand people (Nogueira, 2003).

Since the 1980s, with the weakening of the pig iron processing industry and with the installation of large companies in the city such as Fiat, AmBev, Caterpillar, among others, motivated by the strategic location of the city and its policy of tax exemption, there was a greater diversification of the services sector and a greater dynamism in trade.

Currently, according to data from the Commercial and Industrial Association of Sete Lagoas (ACI, 2015), the city has about 230 thousand inhabitants, mostly urban (97.6\%), with GDP in 2012, corresponding to US\$ 1,6 billion, representing a growth of $317 \%$ in 10 years; and a per capita income, in 2012, of US\$ 7,442.00, evolving 258\%, also in ten years. The city's Human Development Index - HDI in 2010 was 0.76, considered high according to Brazilian perspective.

The Sete Lagoas downtown is a traditional and dynamic commercial hub, characterized as the founding landmark of the city. Despite its wide scope, commerce in this venue is formed by 
two main corridors, comprising the streets Monsenhor Messias and Dr. Emilio de Vasconcelos Costa. These attributes make the study of the city center strategic for the understanding and conceptualization of the socio-spatial environments of the city.

Santa Juliana Street takes importance in the process of expansion of the city towards the suburban area. In this sense, the street is an important axis of economic development, being the main access road between the city center and the industrial plants of the large newly installed companies, and their accessibility to the suppliers, installed on the border of the locality with the neighboring cities. With the implementation of these large industries in the region, since the 1980s, Santa Juliana Street has been experiencing a period of intense economic expansion, with the introduction of diversified stores, including retail stores, construction materials, mechanic workshops, automobile agencies and even bank agencies.

As for its main shopping mall, opened in 2010, it is an evident symbol of the current process of economic conversion of the city. Located 8 minutes from downtown and occupying an area of more than $70 \mathrm{~km}^{2}$, the shopping mall serves, in addition to Sete Lagoas, 23 nearby municipalities. In general terms, it has approximately 80 stores, divided into anchor stores, malls operations which are the kiosks - food services, megastores, and satellite stores. The space is new, modern, and standardized, focused, according to management reports, in bringing a more "sophisticated" space and "higher consumption standard to the city and region".

The characterization of the target spaces of this study makes it pertinent to analyze the data obtained considering conditions of diversity and vitality, as recommended by Jacobs (2011); the way in which social interactions are shaped through the notion of capital (Bourdieu, 2010); and, finally, the analysis of the strategies of action adopted by local entrepreneurs, based on the types of IEIs, as suggested by Lopes and Rosso (2010). 


\section{Downtown}

Concerning the conditions of diversity and vitality, the complex formed by streets Monsenhor Messias and Emílio de Vasconcelos is historically identified as the city's major trade center, mainly due to its geographical location and historical context, since the city has grown around these streets. Other factors explaining the importance of these two streets to local commerce are their strategic location, providing easy access, location, and identification for those arriving in the city of Sete Lagoas and the presence of bus stops on Monsenhor Messias Street, which have been moved from the city's Tourist Assistance Center, to that street, causing a greater flow of people there.

It is also highlighted how the presence of large brand stores works as a factor that attracts public to the city center, thus increasing the flow of people. In the complex of these two streets, it is possible to identify a great concentration of commercial spaces next to each other, such as various stores, popular markets and cafeterias, services such as schools, banks and church, and public services such as bus stops and information service to the public, creating a great diversity of functions: "The movement, there are several types of stores [...] high diversity. It's a lot, huh? Whatever people are looking for they find on this street" (Report, Interview 38).

Moreover, you can visually observe a mix of new and old buildings. It is not difficult to find new entrepreneurs, with modern enterprises and nationwide networks of stores and the traditional entrepreneurs, with long lasting businesses in the city, as traditional drugstores, clothing stores and even the Municipal Market. This condition is observed in reports and photos of the streets of the center area. 
There is also a great and constant movement of people in the center. These people are "lowearning" and they know that they will be able to solve all their problems and make purchases at a price they are able to afford: "It is very popular [the public], it is more popular"; "[...] it is very dynamic. There was an overall drop in trade due to the economic crisis, but the trade here is not bad [...] not agitated at times, busy, hard to find a parking spot" (Report, Interview 34).

In a unanimous way, shopkeepers emphasize that being in the center is great for business, given the tradition this place has of being an excellent business hub, in addition to the conditions of diversity and vitality previously mentioned. Furthermore, the presence of store networks and major brands and professionalization of local businesses appear as a future trend for the city center.

According to Jacobs (2011), this scenario allows the characterization of the city center environment as a dynamic commercial spot, with great diversity and vitality, since all four conditions postulated by the author to obtain such a condition were identified: diversity of functions, short distance blocks, combination of new and old buildings and density of people.

The social interactions in the city center are marked by a conformation of those who have already become accustomed and adapted to the environmental conditions of the city center and do little to change them. They present little dynamic management models, focused on the continuity of what has been done by them for several years, often dictated by the presence of the public in the center, associated with a product with a competitive price and with the great movement of people from the traditional streets of trade for the success of the business around.

As an exception, younger and less time-consuming entrepreneurs in the center seek to carry out a more "modern" management, anchored in concepts such as brand value, value perception among other jargon considered to be important by business schools. In this sense, it is possible to see, on the part of these entrepreneurs, the domain of cultural capital (e.g., formal and intellectual 
cognitive knowledge) as a differential, to the detriment of interpersonal relations (e.g. tacit and relational knowledge), which are intensively present (Nelson, Sant'Anna, Wood, 2016; Stinchfield, Nelson, Wood, 2013; Sarasvathy, 2012; Gertler, 2003).

There is a transitional space where the old one, represented by older commercial practices such as installment plan sales and long-term payment sales, without any type of formal registration, besides creating an atmosphere of proximity and trust with the client, and the modern way, linked to modern management practices and professional training as the main strategy for business survival.

These characteristics of tradition, modernity and transition can be identified in the following reports: "We have a lot of training programs. There is a training for all of the products of the store because they are well differentiated, some products contain salts in them, it is part of what we do, we study about the products" (Report, Interview 35).

It happens a lot [having people asking to buy in long-term payment contracts or credit installments]. Nevertheless, we have our means of payment, right? So, one explains, talks about the advantages of our means of payment also, the forms of payment. In addition, one also has derivative clients, that is a purchase that customers make and as they score, they get the benefit of a discount (Report, Interview 34).

Apparently, the great changes in the city center (downtown), public and private interference, struggles for better conditions for its environment, among others, have already undergone their great cycle of adaptations, therefore, changes in the present context are slower and more gradual than they have been in other times. This makes surviving organizations slower when it comes to making changes. 
It is possible to affirm then that the domain of the social field in downtown Sete Lagoas is governed mainly by the attempt of the dominion of the symbolic capital postulated by Bourdieu (2008). This, considering that the tradition constructed within the passage of time in that one space, considering the clear notion that the population already knows how the area works, leading to a low need for interaction and action, the act of exercising power in the studied field is considered as common Habitus. In short, the capitals observed in downtown may be observed as follows:

1. Economic capital: little presence. Traders and other agents do not use economic power as a field control strategy;

2. Social capital: It was already important, but today it hold little relevance, since there is little interaction between street traders;

3. Cultural capital: present in the business of few traders, who understand modern management practices as a differential;

4. Symbolic capital: very present, based on the tradition that the trade of the city center represents.

In relation to the entrepreneurial ecosystem, it is possible to notice that the relations between the entrepreneurial agents are based on tradition, in dynamic space, aiming at individual gains, with reduced collective concern, since the other has little influence on their action (Mack \& Mayer, 2016). 
As a result, the ecosystem formed in the central region (downtown) can be typified as Protocooperation. It is understood that it is relevant to classify this space as such since in this IEI model the species involved are benefited to some extent by the presence of each other, but they can live independently without the interaction between them in the environment and without prejudice if one of them ceases to exist in the environment.

\section{Santa Juliana Street}

The conditions of diversity and vitality found on Santa Juliana Street allows one to observe a great and constant growth of the street, a result of its own expansion and its condition of a "new center". In the period from 1976 to 1989 , the opening of 30 businesses was registered, with low diversity among them, comprising seven different types of activities as bars, food retail and basic services such as locksmiths, seamstresses and electricians.

Between 1990 and 1995, 67 businesses were opened with 14 distinct types of activities. From 1996 to 2000, 103 businesses were opened, of which 19 were only in 2000, but with little differentiation, being possible to observe only 12 records of different activities. Already into the period between 2001 and 2005, it was registered the opening of 98 businesses, with 15 records of distinct services, still with the domain of retail trade and basic services.

Therefore, the great leap in the diversification and massification of businesses in Santa Juliana Street takes place between the years of 2011 and 2014, when 206 businesses were opened, with 27 different types of business records, showing a trend of great diversification and expansion of the services: "Nowadays it has expanded and if you go past the interchange it seems that it is 
even more dynamic. But there are bigger trades now, right? Bigger [...]" (Report, Interview 7); "[...] I had not put any thought on it, the blocks are actually short." (Report, Interview 21).

It is possible to take notice at Santa Juliana Street, however, two other conditions pointed out by Jacobs (2011) as fundamental to the diversity and vitality of urban spaces: the presence of short blocks and the combination of buildings with different ages and conservation states.

The great flow of people and street dynamics are regarded as a crucial factor for the thriving of Santa Juliana Street as a commercial hub. Entrepreneurs see the growth in street traffic and as a great opportunity to thrive in business: "Because here is one of the best spots, the guy comes down from Vico over there and he just got paid so he goes to the bar. I'm going to check my Facebook first' so the guy stops here.'" (Report, Interview 11). These indications allow us to infer that the environment of Santa Juliana Street has significant diversity and vitality, as suggested by Jacobs (2011).

Social interactions at Santa Juliana Street are marked by an absence of competitiveness. Despite the previously mentioned increase in volume and the diversification of local commerce, local entrepreneurs report that competitiveness among them has not increased. The speech of "healthy competition between them," "mutual aid," "complementarity," and "competition with downtown, not among them," is unanimous among these entrepreneurs.

Even among the businesses that operate in the same branch of activity, there is the discourse that seeks to complement what the other business does not have, and not compete directly, such as one lan-house that is focused on repairing machines and the other one that focuses on online games and equipment, and automotive in which one repairs cars and the other sells accessories: "The competition is friendly [...] One helps another and the coexistence is [the business]. It's more about complementing each other, precisely" (Report, Interview 5). 
The mixture of passersby, the ever-growing expansion, and the neglect of the public sector - characterized by the reports to be analyzed later - bring to the street commerce a series of peculiarities, such as the high diversification of commerce, valuation of real estate, increase in the rent price of stores, constant interference from the public sector, and a need for local shopkeepers to organize their local business (Van de Ven, 1993).

Under the aegis of Bourdieu's capitals (2008), it is possible to see how a symbolic framework that would offer Santa Juliana Street a favorable trade-friendly status has not yet been built. It is possible to take notice among the local entrepreneurs the attempt to create this symbolic capital in a manner that is less anchored in perception, neglect, and confusion, and more in the ease of purchase and complementarity of local businesses; but this is still an incipient construction.

Given this model of relationship among traders and among traders and public, the predominance of social capital among the types of capital proposed by Bourdieu (2008) as an instrument of power in the social field is notorious. It is clear in the reports of local social actors that interpersonal relationships are a recurrent Habitus, and that knowing how to relate well to the various actors found in that extremely dynamic environment is more interesting for the attainment of power than focusing on aspects related to economic or cultural power. The domain of this social capital would awaken among those involved, in that environment, the prestige and the social recognition on the part of the individuals more than any economic or cultural aspect.

At this point, it becomes possible to understand that the domain of symbolic capital in the reality under study would come through the knowledge of the local actors, the trust acquired with time and by the services already rendered to the community, the latter being recognized by the entrepreneurs who are present at Santa Juliana Street. 
The interactions of competition versus complementarity demonstrate how the dynamics in Santa Juliana Street takes place. Because its public is mainly formed by residents of the surroundings and that they are low-income people, the established relationship with the client becomes an important organizational asset and, in this context, competing seems not to be the best strategy.

Concerning the entrepreneurial ecosystem formed on Santa Juliana Street there is a major presence of social interactions developed within a dynamic space, aiming at mutual perks among those involved - in this case, avoiding the need of individuals to move to the center of the city, identified as a competitor, to consume. This allows the ecosystem formed on Santa Juliana Street to be better configured by the Mutualism interaction.

It is plausible to understand this IEI as a representative of Santa Juliana Street as all the social agents present there benefit directly from the presence of each other. Since it decreases the frequency, with which the possible consumers of the local commerce go to other environments such as downtown or the mall - to consume products that can be found on the street.

\section{Shopping Mall}

As far as the conditions of diversity and vitality are concerned it is possible to state that the consuming crowd at the shopping mall is characterized as diverse by interviewers. They are more demanding than the street trade public, and often enjoy greater comfort. This would be confirmed by the so-called high-end stores that have closed recently because they were "inadequate to the local public, since this type of consuming public would do their shopping in the capital city of the 
state [Belo Horizonte]. At first, they would come to the store, but then whoever has money in the city goes to Belo Horizonte" (Report, Interview 39).

There is also little presence of consumers in this space. Constantly there are wide, completely empty corridors, which has been bothering local shopkeepers, even arising comparisons to downtown, identifying it as a space where there is more movement: "So we still have this difficulty in trying to bring over this customer, what is difficult at the moment is to make people spend more money on public transportation" (Report, Interview 44).

In a general sense it is notoriously a low dynamic environment, since the conditions postulated by Jacobs (2011) are partially observed: the environment is totally planned and controlled with standardized blocks and other totally architected circulation spaces. There is no mixture of new and old constructions, all of which are new, there is little movement of people and the diversity of functions is still in expansion.

Regarding the interaction between space and the public - social interactions - the idea of shopkeepers that the population of Sete Lagoas does not seem to have understood properly the proposition of this environment is of relevant discussion (Pennings, 1982). It is a strong idea that the concept of a shopping mall would still be a "foreign body" to the city, better accustomed to the street commerce and its own features, quite different from those found at the mall.

These shopkeepers identify that the population understands that prices in the mall are higher, which would not be true, and that there is the challenge of accustoming the population to this new space, since people seem to believe that they are "not good enough" to visit such a "sophisticated" space, causing the public not to go into the shopping center: "Why do I think it [the mall] is empty? Because I think people choose to come down here, there are more possibilities, 
options, they get to browse more. There are really enthusiastic about coming to the city center 'oh I'm just going to browse' [...]" (Report, Interview 45).

In addition, more modern forms of management (Zahra \& Nambisan, 2012) are shown to be more common in this space when compared to downtown. Reports from shopkeepers who work at the mall and work or have worked at downtown show how this distinction of managerial culture is more present in the mall, whether due to managing practices or due to the public's demand.

Based on these findings, there are indications that the space formed by the shopping mall is based on cultural (e.g., intellectual) capital to control the social field. This domination, apparently, does not prove to be efficient, for the local public does not perceive any symbolic value in the conditions of attraction provided by this capital, such as modern management practices and standardization of service, environment, and prices.

However, economic capital is little present. Traders and other agents do not use as expected the economic power as a field control strategy. Besides, social capital is also little present, since there is little interaction among shopkeepers, being possible to observe it only in the act of the sale. Symbolic capital, in its turn, is present in a truly little beneficial manner to the local commerce, for the local public associates the mall to an expensive and overly sophisticated place rather than a place with the purchasing facilities and readiness as identified by the entrepreneurs there.

On the analysis of the entrepreneurial ecosystem, the shopping mall is strategically implanted in Sete Lagoas with an apparently different proposition from the usual consumption found downtown. As a response, the local public does not seem to have identified with this proposal. The ecosystem present in the space of the mall seems to be closed when it comes to great changes, homeostatic and isomorphic, anchored in the idea that the local population will naturally identify the benefits of consuming in this space to the detriment of others. This space seems to 
exemplify, in Sete Lagoas, the conflict between the factors linked to the traditional, represented by the old and traditional ways of coexistence and consumption of the local agents in the traditional centers of commerce; and the modern, represented by the professionalization and the new models of management, still in process of construction and assimilation by this public.

Finally, in the exercise of conceptualizing such ecosystem, it is possible to observe an interaction among shopkeepers like downtown, which infers that this interaction has even been "imported" from that space, characterized as Protocooperation. However, in addition to this interaction, it is possible to observe some tension among shopkeepers and the management of this space, to which shopkeepers must pay rent to be present, and they believe that this resource is sometimes used for their benefit but at other times such investment is not fruitful.

This peculiarity, in which certain organizations are submitted to a more powerful host that owns power to determine the rules of the interaction, brings to the fore the concepts of "slavery". There is the perception that the interaction is not harmonious between the host - in this case the shopping mall - and the organizations, which are hosted, in this case, its tenants.

Despite these two typologies being noticed and punctuated, as a rule it may be observed among the tenant shopkeepers a perception of benefit in being hosted by the mall, mainly motivated by the future perspectives for this space, without causing damage to the host, in this case, the mall itself. In a general way, the tenants perceive perks in being lodged in the shopping mall and, should any tenants cease to exist, the host organization, in this case the mall, would not be seriously affected. This interaction is close to Inquilinism, as the type of IEI that better characterizes the entrepreneurial ecosystem present in the space of the shopping mall.

To summarize, the three ecosystem models found in the present study are visually put together in Figure 2. 
Insert Figure 2 about here.

As synthesized in Figure 2, within the space of the city center (downtown), the combination of a great environment of diversity and vitality dominated by symbolic capital, constitutes a Protocooperative ecosystem, in which the organizations coexist harmoniously, but without great interaction and without the need of such interaction for survival.

At Santa Juliana Street, the great diversity and vitality, along with the preponderance of the social capital, form an ecosystem mostly Mutualistic, in which there is great social interaction aiming at the survival of the organizations present there.

Finally, in the shopping mall, the conditions of diversity and vitality are less present and combined with cultural (e.g., intellectual) capital, they form an Inquiline ecosystem. In it, the tenant, that is, the "inquiline organization" benefits directly from the presence of another host organization, without causing any damage to the latter. However, it would suffer great damage, should this host cease to exist. Meanwhile the "host organization" is not strongly affected, should the tenant cease to exist.

In a general way, the cases studied presents distinct ecosystems. All of them, however, present little competitiveness and seeking to operationalize friendly interactions among the consolidated and newcomers' entrepreneurs, following the city Habitus and traditions as a whole (Nelson, Sant'Anna, Wood, 2016; Stinchfield, Nelson, Wood, 2013; Sarasvathy, 2012; Gertler, 2003). 
The implication is that prior theoretical explanations for entrepreneurial thinking and action hold less explanatory power in bounded ecosystems because they fail to include the micro versus meso versus transversal versus macro interactions between the variables articulated in our model. The connection between this study and extant thinking emerges from the realization that the entrepreneurs' backgrounds (downtown, Santa Juliana Street, and Shopping Mall) and social identities come together with the sociocultural fabric of the macro context to spawn distinct types of entrepreneurs in distinct types of ecological interactions who share common Habitus. In this direction, our findings suggest that there may be many different types of "entrepreneurial dimensions" and these are not only a function of the individual (micro level) but also a function of the meso circumstances (specific ecosystem), macro circumstances (macro context level), and Habitus (transversal level) in and with which they interact.

Considering the mainstream of research on community social ecology, quoted in entrepreneurship, focuses on the dynamics of new sectors and highlights relationships between suppliers, vertical movements, competitive movements, personnel flows, information, and resources among agents, such as the most significant aspects (Freeman \& Audia, 2006; Mezias \& Kupferman, 2001; Owen-Smith \& Powell, 2004).

In this study, the focus is different. We study ecosystems based on the physical space, within which diverse range of entrepreneurs live and work. In this case we find that competition, supplier relationships, personnel and resource flows were insignificant in terms of the tensions and main issues identified by entrepreneurs in the areas. Thus, instead of the evolution of an ecosystem being linked only to the competitive dynamics of a given sector, would also be linked to the personal capitals and Habitus of its entrepreneurs, as well as last resort, to the capacity and will to mobilize social and politically (Saravasthy, 2004). 
Another important result of this study is that the individuals personified in the different types of entrepreneurs do not arise, nor act in a social vacuum, nor are they independent of one another, especially in contexts where they share the same historical or cultural heritage (Habitus). They are part of a community social ecology (Hannan \& Freeman, 1984), full of competition, as well as intentional and unconscious synergies. While each type of identified entrepreneur has its role, its objectives, mobilize different capitals and produce their impacts, they coexist in a state of tension dynamics.

The classic literature on entrepreneurship does not seem, however, very attentive to the coexistence and tension between different types of entrepreneurs. At the same time, it does not consider community ecology in creating contexts that contribute to interaction between these agents and their social role.

Our findings are also quite different from the two extremes that characterize traditional thinking about the entrepreneurship. On the one hand, the view of entrepreneurs as quasi-mythical elements, unlike of the other individuals, who by their genius and singular skills would be able to identify and enjoy opportunities and create new wealth that others would not be able to see. On the other hand, the idea that the macro technological and economic forces would create opportunities for new ventures, which are idealized at random by persons other than by virtues happen to be in the right place at the right time. Example in this line would be the mentioned studies on social ecology community (Hannan \& Freeman, 1984; Freeman \& Audia, 2006). Undoubtedly, the accidents of history and geography forge configurations of physical and technological infraestructure in a unique way. To verify that different entrepreneurs are inserted in social contexts, in which their agents have different and conflicting roles, seems to us not to be the only contribution of this study. It is evident, also, that the entrepreneur depends on his 
environment in a way (e.g., articulating macro, meso, micro, and transversal dimensions) not yet explicit in the literature.

\section{CONCLUSION}

From the set of data obtained, it is stated that the interactions among the different social agents investigated in the three spatialities of this present study display distinctions anchored in the local cultural praxis of each environment, evidencing distinct capitals mobilized, influenced by specific environmental conditions (Van de Ven, 1993) as well as Sete Lagoas macro context Habitus and business traditions (Bourdieu, 2008).

This finding, on the one hand, reinforces the importance of the environment in the establishment of different social dynamism thus, therefore, of entrepreneurial dynamics, as well as the relevance of Bourdieu's notions of Habitus, for the analysis of entrepreneurial ecosystems and its interactions.

In other terms, the findings and results corroborate space as an important "capital", that is, as a relevant factor to the vitality of entrepreneurial ecosystems. Likewise, they reiterate the relevance of relationships among agents, and the understanding of how these interactions are fundamental for interventions. Furthermore, they suggest an approach for the analysis of the environment, through the consideration of interspecific ecological interactions - IEIs, which point out the importance of processes - such as entropy and isomorphism (Nicholls, 2010) - as well as giving to local agents the understanding of social dynamics - historical, economic, and spatial experiences (Jacobs, 2011; Bourdieu, 2008). 
The findings from our study should be viewed considering a number of limitations, many of which are inherent to qualitative research and have been discussed in detail elsewhere (Eisenhardt, 1989; Eisenhardt \& Graebner, 2007). In this case, an additional potential limitation is that our theory is in many ways "local" (i.e., it has greater explanatory value and application for the specifics situations studied). That said our findings parallel themes found in other studies. As such, we believe that it touches on themes in ways that current entrepreneurship theory has not recognized. To that end, we note that some of the dynamics observed parallel those seen in developed economies, yet others have not been noted in the literature conventionally adopted. As such we suspect that other entrepreneurial ecosystems in developed and developing economies harbor similarly complex sociocultural context-entrepreneur interactions. This is likely especially true of those that experience rapid growth. As such, we believe that our study provides in-depth insight into how micro, meso, macro, and transversal socio spatial dimensions come together to spawn distinct types of interspecific ecological interactions and mindsets and why these differences play an important role in models of interspecific ecological interactions and entrepreneurs thinking and action.

Finally, the findings and results indicate the need for new empirical analyzes that allow the validation of the reported categories and different types of ecosystem interactions, considering the influence of the context, technology, and innovation (Autio, Kenny, Mustar, Siegel, Wright, 2014) as well as the historical trajectories and Habitus that characterize the social system (Olaru \& Purchase, 2015; Stam, 2015; Bourdieu, 2010; Storper, 1995). 


\section{REFERENCES}

ACI, Commercial and Industrial Association of Sete Lagoas (2015). Sete Lagoas in numbers: a collection of the main indicators in recent years. Sete Lagoas, MG: ACI-SL.

Autio, E.; Kenny, M.; Mustar, P.; Siegel, D.; \& Wright, M. (2014) Entrepreneurial innovation: the importance of context. Research Policy, 43(1): 1097-1108.

Bataglia, W.; Franklin, M. A.; Caldeira, A.; \& Da Silva, A. A. (2009) Implications of environmental theories for strategic management. Revista Eletrônica de Gestão Organizacional, 7(3): 314-330.

Baum, J. A. C. (1999) Organizational ecology. In: Clegg, S. R.; \& Hardy, C. (Eds.). Studying organization: theory and method. London: Sage Publications.

Benbasat, I.; Goldstein, D.; \& Mead, M. (1987). The case research strategy in studies of information systems. MIS Quarterly, 11(3): 369-386.

Bourdieu, P. (2008) The distinction: social critique of judgment. Porto Alegre, RS: Zouk.

Bourdieu, P. (2009) The practical sense. Petrópolis, RJ: Vozes.

Bourdieu, P. (2010) The symbolic power. Rio de Janeiro: Bertrand Brasil.

Carland, J.; Carland, J. D.; \& Stewart, W. (1996) Seeing what's not there: the enigma of entrepreneurship. Journal of Small Business Strategy, 7(1): 1-20.

Collins, O.; \& Moore, D. (1964) The enterprising man. East Lansing, MI: Michigan State University Press.

Cunha, M. P. (1999) Organizational ecology: implications for management and some clues to overcoming its anti-management character. Revista de Administração de Empresas, 39(4): 21-28. 
Denzin, N.; \& Lincoln, Y. (2000). Handbook of qualitative research. Thousand Oaks, CA: Sage.

Emerson, R.; Fretz, R.; \& Shaw, L. (1995). Writing ethnographic fieldnotes. Chicago, IL: University Chicago Press.

Eisenhardt, K. (1989). Building theories from case study research. Academy of Management Review, 14(1): 532-550.

Eisenhardt, K.; \& Graebner, M. (2007). Theory building from cases: Opportunities and challenges. Academy of Management Journal, 50(1): 25-32.

Freeman, J. H.; \& Audia, P. G. (2006) Community ecology and the sociology of organizations. Annual Review of Sociology, 32(1): 45-169

Gertler, M. S. (2003). Tacit knowledge and the economic geography of context, or the undefinable tacitness of being (there). Journal of Economic Geography, 3(1): 75-99.

Glaser, B.; \& Strauss, A. (1967). The discovery of grounded theory: strategies for qualitative research. New York, NY: Aldine de Gruyter.

Håkansson, H.; \& Snehota, I. (1995). Developing relationships in business networks. London: Thomson Business Press.

Hannan, M. T.; \& Freeman, J. (1984) Structural inertia and organizational change. American Sociological Review, 49(2): 149-164.

Hannan, M. T.; \& Freeman, J. (1977) The population ecology of organizations. American Journal of Sociology, 82(5): 929-964.

Hess, M. (2004). 'Spatial' relationships? Towards a reconceptualization of embeddedness. Progress in Human Geography, 28(2): 165-186. 
Hull, D.; Bosley, J.; \& Udell, G. (1980) Renewing the hunt for the heffalump: Identifying potential entrepreneurs by personality characteristics. Journal of Small Business Management, 18(1): 11-18.

Jacobs, J. (2011). The death and life of great cities. São Paulo: Martins Fontes.

Kanter, R. M. (2012) Enriching the ecosystem. Harvard Business Review, 90(3): 140-147.

Lopes, S.; \& Rosso, S. (2010). Bio: classic sequence. São Paulo: Saraiva.

Mack, E.; \& Mayer, H. (2016) The evolutionary dynamics of entrepreneurial ecosystems. Urban Studies, 53(10): 2118-2133.

Mezias, S. J.; Kuperman, J. (2001) Economic action and social structure: the problem of embeddedness. American Journal of Sociology, 91(3): 481-510.

Miller, D. (1983) The correlates of entrepreneurship in three types of firms. Management Science, 29(7): 770-791.

Moore, J. (1993) Predators and prey: a new ecology of competition. Harvard Business Review: 71(3): 75-86.

Nelson, R. E.; Sant'Anna, A. S.; Wood, M. S. Sociocultural context, entrepreneur types, mindsets, and entrepreneurial action in Tiradentes, Brazil. In: A. Corbett \& J. Katz (Eds.) Advances in entrepreneurship, firm emergence, and growth, 18(1): 33-74.

Nicholls, A. (2010) The legitimacy of social entrepreneurship: reflexive isomorphism in a preparadigmatic. Entrepreneurship Theory and Practice, 34(4): 611-633.

Nogueira, M. (2003) Sete Lagoas: The functional dynamics of a place in the urban network of Minas Gerais. Rio de Janeiro: UFRJ.

Olaru, D.; \& Purchase, S. (2015) Innovation network trajectories: the role of time and history. Journal of Business Industrial Marketing, 30(3/4): 342-353. 
Patton, M. (1990). Qualitative evaluation and research methods. Newbury Park, CA: Sage.

Pennings, J. M. (1982) The urban quality of life and entrepreneurship. Academy of Management Journal, 25(1): 63-79.

Sarasvathy, S. (2012). Worldmaking. In: Corbett, A.; \& Katz, J. (Eds.). Advances in Entrepreneurship, Firm Emergence and Growth, 14(1): 1-24.

Sarasvathy, S. (2004) The questions we ask and the questions we care about: reformulating some problems in entrepreneurship research. Journal of Business Venturing, 19(1): 707-717.

Schumpeter, J. (1950) Capitalism, socialism, and democracy. Harper: New York.

Spigel, B. (2017) The relational organization of entrepreneurial ecosystems. Entrepreneurship Theory Practice, 41(1): 49-72.

Stam, E. (2015) Entrepreneurial ecosystems and regional policy: a sympathetic critique. European Planning Studies, 23(9): 1-11

Stinchfield, B. T.; Nelson, R. E.; Wood, M. S. (2013) Learning from Levi-Strauss' legacy: art, craft, engineering, bricolage, and brokerage in entrepreneurship. Entrepreneurship Theory and Practice, 37(1): 889-921.

Tureta, C.; Rosa, A. R.; \& Ávila, S. C. (2006) From systemic theory to the concept of interorganizational networks: an exploratory study of the theory of organizations. Revista de Administração da Unimep. 4(1): 1-16.

Van de Ven, A. H. (1993) The development of an infrastructure for entrepreneurship. Journal of Business Venturing, 8(1): 211-230.

Zahra, S.; \& Nambisan, S. (2012). Entrepreneurship and strategic thinking in business ecosystems. Business Horizons, 55(1): 1-16. 
FIGURE 1

Entrepreneurial Ecosystem Development Model

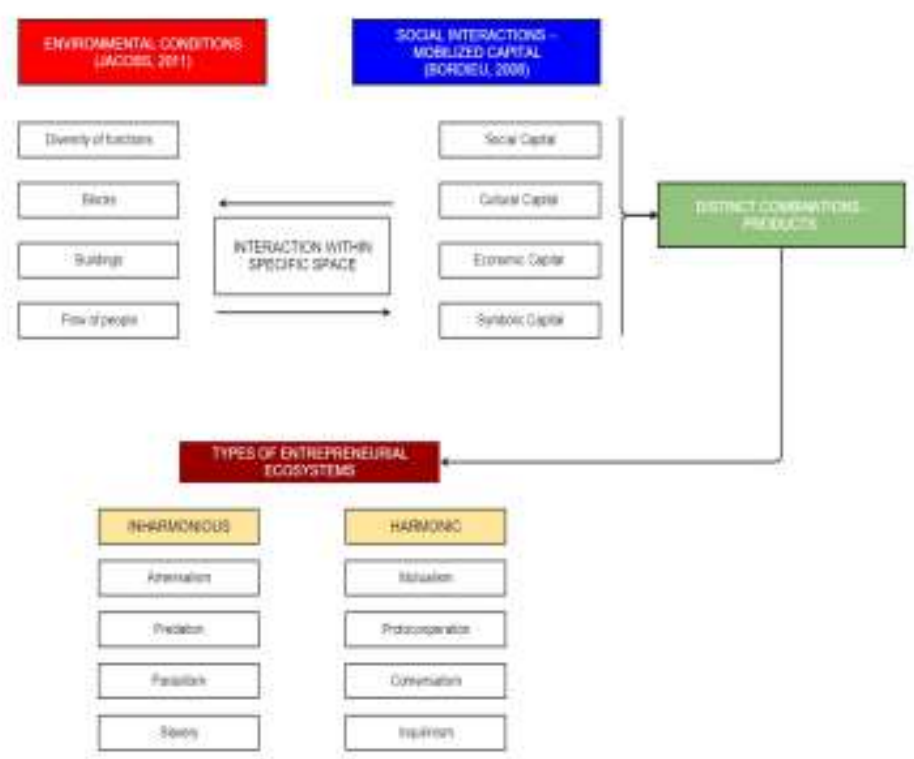

FIGURE 2

Entrepreneurial Ecosystems of the three analyzed spaces

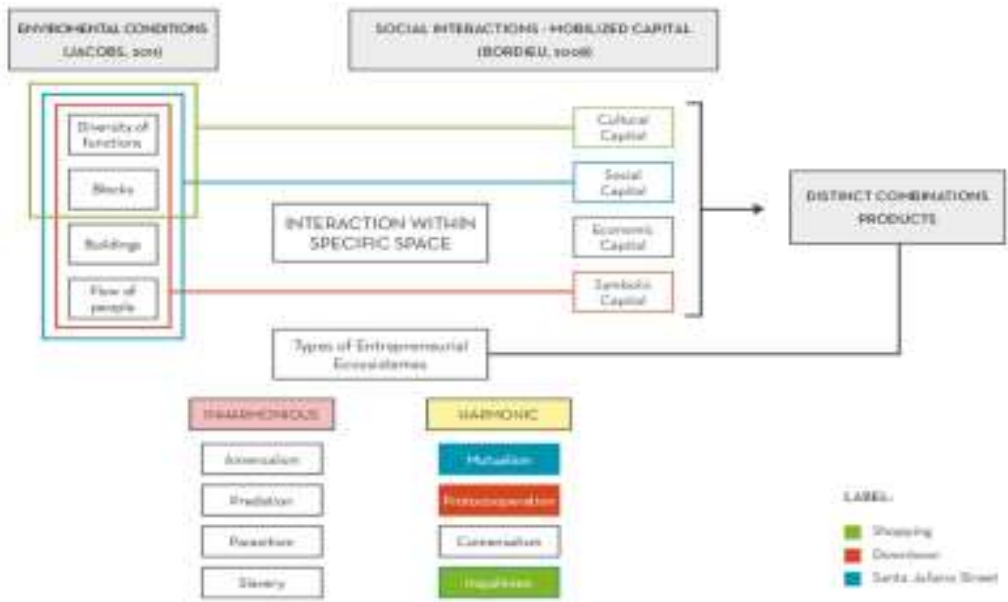

